\title{
Identification of Polycystin-2 and CFTR common targets
}

\author{
M Roxo-Rosa ${ }^{*}$, SS Lopes \\ From Cilia 2014 - Second International Conference \\ Paris, France. 18-21 November 2014
}

Autosomal-Dominant-Polycystic-Kidney-Disease type-II (ADPKD-II) is caused by mutations in the Polycystin-2 (PC2) encoding gene. The dysfunction of this $\mathrm{Ca}^{2+}$-conducting channel leads to the formation of fluid-filled renal cysts (1). Through poorly known mechanisms, cystogenesis entails an overstimulation of Cystic-Fibrosis-Transmembrane-conductance-Regulator (CFTR), a key $\mathrm{Cl}^{-}$-channel in epithelia's ion/fluid transport (2). To study PC2-CFTR crosstalk we used the zebrafish embryonic node (Kupffer's Vesicle, KV) as a model system. Both proteins are required for KV proper function $(3,4)$.

\section{Objective}

To determine common gene targets of PC2 and CFTR specific knockdown.

\section{Methods}

foxj1a:gfp transgenic zebrafish embryos (5) were injected with antisense morpholinos against $p c 2$ (augMO-pc2) or $c f t r$ (augMO-cftr). This strain offers a KV specific GFP-reporter at 10-11 somites stage. KV cells were isolated by Fluorescent-Activated-Cell-Sorting (FACSAria High-Speed Cell Sorter, BD). Cells from noninjected and mismatch-MO injected embryos were used as controls. Total RNA was extracted (RNAeasy kit, Qiagen) and tested for its quality (Agilent 2100 Bioanalyzer, Affymetrics). Transcriptomes were assessed with the Zebrafish Gene 1.1 ST Array Strip (Affymetrics).

\section{Results}

$\sim 2$ ng of each morpholino were required to efficiently reduce the $\mathrm{PC} 2$ and CFTR expression. In agreement to the literature $(3,4)$, the augMO-pc2 induced curly-up tails and the augMO-cftr prevented the proper KV lumen expansion. In both cases laterality defects were observed. We have novel information on differentially transcribed genes that we are validating by qPCR.

\section{Conclusions}

Among the PC2- and CFTR-knockdown overlapping targets, we found genes encoding proteins involved in the Calmodulin-mediated $\mathrm{Ca}^{2+}$-signalling. These could be involved in the PC2-CFTR crosstalk.

\section{Acknowledgements}

Supported by FCT-ANR/BEX-BID/0153/2012 grant.

Published: 13 July 2015

References

1. Harris PC, Torres VE: Genetic mechanisms and signaling pathways in autosomal dominant polycystic kidney disease. J Clin Invest 2014, 124(6):2315-2324.

2. Chang MY, Ong AC: New treatments for autosomal dominant polycystic kidney disease. J Clin Pharmacol 2013, 76(4):524-535.

3. Schottenfeld J, Sullivan-Brown J, Burdine RD: Zebrafish curly up encodes a Pkd2 ortholog that restricts left-side-specific expression of southpaw. Development 2007, 134(8):1605-1615.

4. Navis A, Marjoram L, Bagnat M: Cftr controls lumen expansion and function of Kupffer's vesicle in zebrafish. Development 2013, 140(8):1703-1712.

5. Caron $A, X u X$, Lin $X:$ Wnt/B-catenin signaling directly regulates Foxj1 expression and ciliogenesis in zebrafish Kupffer's vesicle. Development 2012, 139:514-524.

doi:10.1186/2046-2530-4-S1-P4

Cite this article as: Roxo-Rosa and Lopes: Identification of Polycystin-2 and CFTR common targets. Cilia 2015 4(Suppl 1):P4. 